\title{
Effects of the cooperative interaction on the diffusion of hydrogen on $\mathrm{MgO}(100)$
}

\author{
Castelli, Ivano E.; Soriga, Stefan G.; Man, Isabela C.
}

Published in:

Journal of Chemical Physics

Link to article, DOI:

$10.1063 / 1.5029329$

Publication date:

2018

Document Version

Publisher's PDF, also known as Version of record

Link back to DTU Orbit

Citation $(A P A)$ :

Castelli, I. E., Soriga, S. G., \& Man, I. C. (2018). Effects of the cooperative interaction on the diffusion of hydrogen on MgO(100). Journal of Chemical Physics, 149(3), [034704]. https://doi.org/10.1063/1.5029329

\section{General rights}

Copyright and moral rights for the publications made accessible in the public portal are retained by the authors and/or other copyright owners and it is a condition of accessing publications that users recognise and abide by the legal requirements associated with these rights.

- Users may download and print one copy of any publication from the public portal for the purpose of private study or research.

- You may not further distribute the material or use it for any profit-making activity or commercial gain

- You may freely distribute the URL identifying the publication in the public portal

If you believe that this document breaches copyright please contact us providing details, and we will remove access to the work immediately and investigate your claim. 


\section{Effects of the cooperative interaction on the diffusion of hydrogen on $\mathrm{MgO}(100)$}

Ivano E. Castelli, Stefan G. Soriga, and Isabela C. Man

Citation: The Journal of Chemical Physics 149, 034704 (2018); doi: 10.1063/1.5029329

View online: https://doi.org/10.1063/1.5029329

View Table of Contents: http://aip.scitation.org/toc/jcp/149/3

Published by the American Institute of Physics

\section{Articles you may be interested in}

From $\mathrm{C}_{60}$ "trilliumons" to "trilliumenes:" Self-assembly of 2D fullerene nanostructures on metal-covered silicon and germanium

The Journal of Chemical Physics 149, 034702 (2018); 10.1063/1.5038790

Chirality at two-dimensional surfaces: A perspective from small molecule alcohol assembly on $\mathrm{Au}(111)$

The Journal of Chemical Physics 149, 034703 (2018); 10.1063/1.5035500

Transient structured fluctuations in a two-dimensional system with multiple ordered phases

The Journal of Chemical Physics 149, 034503 (2018); 10.1063/1.5026680

Learning dynamic Boltzmann distributions as reduced models of spatial chemical kinetics

The Journal of Chemical Physics 149, 034107 (2018); 10.1063/1.5026403

Potential of mean force for two nanocrystals: Core geometry and size, hydrocarbon unsaturation, and universality with respect to the force field

The Journal of Chemical Physics 149, 034109 (2018); 10.1063/1.5039495

Communication: Computing the Helmholtz capacitance of charged insulator-electrolyte interfaces from the supercell polarization

The Journal of Chemical Physics 149, 031103 (2018); 10.1063/1.5038639

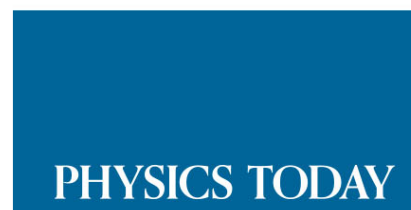

WHITEPAPERS
ADVANCED LIGHT CURE ADHESIVES

Take a closer look at what these environmentally friendly adhesive systems can do
READ NOW

PRESENTED BY

Q MASTERBOND 


\title{
Effects of the cooperative interaction on the diffusion of hydrogen on $\mathrm{MgO}(100)$
}

\author{
Ivano E. Castelli, ${ }^{1}$ Stefan G. Soriga, ${ }^{2}$ and Isabela C. Man ${ }^{3, a)}$ \\ ${ }^{1}$ Department of Energy Conversion and Storage, Technical University of Denmark, \\ DK-2800 Kongens Lyngby, Denmark \\ ${ }^{2}$ Centre for Technology Transfer in the Process Industries, University Politehnica of Bucharest, \\ 1, Gheorghe Polizu Street, Building A, Room A056, RO-011061 Bucharest, Romania \\ 3 “C. D. Nenitzescu” Center of Organic Chemistry, Romanian Academy, 202B Splai Independentei, \\ RO-060023 Bucharest, Romania
}

(Received 13 March 2018; accepted 29 June 2018; published online 20 July 2018)

\begin{abstract}
Understanding hydrogen diffusion is important for applications such as hydrogen storage and spillover materials. On semiconductors, where paired electron acceptors and donors stabilize each other, the hydrogen diffusion depends on the number of adsorbed fragments. Using density functional theory, we investigate the effects of preadsorbed hydrogens on activation energy and reaction path for hydrogen diffusion on $\mathrm{MgO}(100)$ : the presence of an unpaired hydrogen causes a diffusion, on O-sites, above the surface with a lower activation energy compared to the case of paired hydrogens where the diffusion distorts the surface. This effect is missing for diffusion on Mg-sites. Published by AIP Publishing. https://doi.org/10.1063/1.5029329
\end{abstract}

\section{INTRODUCTION}

Due to theoretical and experimental advantages, $\mathrm{MgO}$ surfaces have become a prototypical model system for detailed investigations of different features in catalysis such as basicity testing, charge transfer, $\mathrm{CO}_{2}$ activation, and $\mathrm{H}_{2} \mathrm{O}$ dissociation on simple doped or thin film $\mathrm{MgO} .{ }^{1-7}$ The presence of hydrogen on solid surfaces is of key importance for several processes like heterogeneous catalysis, hydrogen storage fuel cells, and sensors. ${ }^{8-10}$ Understanding the adsorption of hydrogen is important for various processes such as the dissociation/recombination of hydrogen, direct X-H dissociation of molecules (e.g. methanol and water), hydrogen abstraction by the surface from different molecules (e.g. $\mathrm{CH}_{4}{ }^{11}$ ), and hydrogen spillover. ${ }^{12-14}$

A possible application of hydrogen on $\mathrm{MgO}$ is related to the use of magnesium and its alloys as hydrogen storage materials. ${ }^{15,16}$ These metals are usually covered with a stable oxide skin when they are exposed to air, water, and oxygen. ${ }^{17,18}$ The interaction of a hydrogen atom/hydrogen molecule and of hydrogen containing molecules with $\mathrm{MgO}$ were widely studied either at experimental and theoretical levels. ${ }^{3,4,6,18-24}$ In this context, $\mathrm{H}$ diffusion has importance in the economy of the entire process.

The adsorption of one atomic $\mathrm{H}$ on the non-polar $\mathrm{MgO}(100)$ surface takes place on top of the oxygen surface atom. It results in spontaneous ionization and the Fermi level shifts to the conduction band edge because an extra electron is added to the system. ${ }^{25-28}$ When $2 \mathrm{H}$ are co-adsorbed, in the ground state configuration, one hydrogen atom binds

\footnotetext{
a) Author to whom correspondence should be addressed: isabela.traistaru@ ccodn.ro and isabelac.man@gmail.com. Telephone: +4021 3167900.
}

to the $\mathrm{O}$ site (forming $\mathrm{H}^{+}-\mathrm{O}^{2-}$ ), while the other is stabilized by binding to the $\mathrm{Mg}$ site (forming $\mathrm{H}^{-}-\mathrm{Mg}^{2+}$ ), and an electron donor and acceptor pair is formed $\left(\mathrm{H}^{+}-\mathrm{H}^{-}\right.$pair, i.e., the hydrogens are paired). ${ }^{27}$ In this way, the Fermi level remains in the middle of the gap and the bandgap of the material is preserved. The evidence for heterolytic splitting of $\mathrm{H}_{2}$ was reported a long time ago by experiments performed on $\mathrm{MgO}$ powders ${ }^{22,29}$ and by $a b$ initio calculations. . $^{20,24,30,31}$

It was shown from ab initio calculations that co-adsorption of fragments enhances significantly their adsorption energies compared to the sum of binding atoms/fragments when alone on the surface, even when the fragments are positioned at non interacting distance from each other ${ }^{32-36}$ (e.g., $\Delta \mathrm{E}_{1 \mathrm{Hm}}+\Delta \mathrm{E}_{1 \mathrm{Ho}} \gg \Delta \mathrm{E}_{1 \mathrm{Ho}-1 \mathrm{Hm}}$, where $\Delta \mathrm{E}$ indicates the adsorption energy and $\mathrm{Ho}$ and $\mathrm{Hm}$ indicate $\mathrm{H}$ adsorbed on $\mathrm{O}-$ and $\mathrm{Mg}$-site, respectively). This effect is called interaction/cooperative/pairing energy $\left(\Delta \mathrm{E}_{\text {pairing }}\right)$ and has been shown to exist on a number of oxide surfaces and electron donor and acceptor fragments to have a one-to-one correlation with the value of the bandgap. ${ }^{26}$

In this work, we go beyond the effects of the cooperative adsorption on the binding energy and we investigate the impact of co-adsorbates on $\mathrm{H}$ diffusion on a $\mathrm{MgO}(100)$ surface, which is an elementary step in surface chemical reactions. The diffusion of $\mathrm{H}$ has been previously studied but, so far, the effects of co-adsorption have not been considered.

We analyze the diffusion of hydrogen both from one oxygen to the other and from one $\mathrm{Mg}$ to the other in the presence of up to three $\mathrm{H}$ atoms previously adsorbed in their ground state configuration (in the following, we will use the Ho notation for $\mathrm{H}$ binding on $\mathrm{O}$ and $\mathrm{Hm}$ for $\mathrm{H}$ binding on an $\mathrm{Mg}$ site) and placed at non-interacting distance from each other. 
First, we show that the transition state (TS) of H hopping on O-sites is different when odd $(1 \mathrm{Ho}$ and $2 \mathrm{Ho}-1 \mathrm{Hm}$, with an unpaired $\mathrm{H}$ that sits on oxygen) or even (1Ho- $1 \mathrm{Hm}$ and $2 \mathrm{Ho}-2 \mathrm{Hm}$, with paired $\mathrm{H}$ ) number of hydrogen atoms are adsorbed. The situation with unpaired and paired $\mathrm{H}$ atom is highly possible to be encountered during the spillover process and also in dehydrogenation of different molecules (alternating the number of $\mathrm{H}$ atoms on the surface from even to odd). The influence of other fragments $\left(\mathrm{OH}\right.$ and $\left.\mathrm{CH}_{3} \mathrm{O}\right)$ on TS is also investigated. Second, we examine the $\mathrm{H}$ diffusion on $\mathrm{Mg}$ sites when one and two $\mathrm{H}$ atoms are preadsorbed on oxygen for the ground state configuration (1Ho- $1 \mathrm{Hm}$ and $2 \mathrm{Ho}-1 \mathrm{Hm}$ ). We show that this type of diffusion has the lowest activation energy (compared to diffusion on O-sites), and its value does not change with the number of preadsorbed $\mathrm{H}$ atoms on oxygen sites.

\section{METHODS}

Density Functional Theory (DFT) calculations are performed using the GPAW code ${ }^{37,38}$ and the Atomic Simulation Environment (ASE).$^{39}$ The core electrons are described by the projector augmented wave (PAW) method, and the Kohn-Sham valence states are expanded in real space uniform grids, with a grid spacing of $0.2 \AA$. All the calculations are performed using spin-polarized revised-Perdew-Burke Ernzernhof functional as exchange and correlation functional $\left(\mathrm{RPBE}^{40}\right)$. It has been shown that the generalized gradient approximation (GGA) RPBE exchange-correlation functional performs well in the prediction of chemisorption properties. It is known that GGA calculations due to self-interaction errors underestimate bandgaps. It has been shown in a previous work where GGA and hybrid functionals have been used to study the charging of gold atom on doped $\mathrm{MgO}$ and $\mathrm{CaO}$ that although the bandgap is not accurately described with GGA functionals and only hybrids can reproduce the correct values, the donor properties of the transition metal impurity are independent on the functional used. ${ }^{1,2}$ Moreover, it has been reported that the most accurate adsorption energies of small molecules (CO, $\mathrm{NO}, \mathrm{CH}_{4}, \mathrm{H}_{2} \mathrm{O}$ ) on $\mathrm{MgO}(100)$ is obtained using BEEF-vdW and random phase approximation (RPA) calculations out of a pool of methods which include local density approximation (LDA), GGA (PBE, RPBE, PBEsol, BEEF-vdW), hybrid functional (HSE06), random phase approximation (RPA). ${ }^{41}$ We thus performed benchmarking calculations on $1 \mathrm{Ho}$ and 1 Ho-1Hm systems using BEEF-vdW functional. ${ }^{42}$ The adsorbates in the initial/final states are slightly stronger bonded than those calculated with RPBE [differential adsorption energies are $\delta \mathrm{E}_{\mathrm{Ho}, \mathrm{BEEF}-\mathrm{vdW}}=1.42 \mathrm{eV}$ vs. $\delta \mathrm{E}_{\mathrm{Ho}, \mathrm{RPBE}}=1.56 \mathrm{eV}$ for Ho on clean $\mathrm{MgO}(100)$ and $\delta \mathrm{E}_{\mathrm{Ho}, \mathrm{BEEF}-\mathrm{vdW}}=-0.44 \mathrm{eV}$ vs. $\delta \mathrm{E}_{\mathrm{Ho}, \mathrm{RPBE}}$ $=-0.37 \mathrm{eV}$ for $\mathrm{Ho}$ on $\mathrm{MgO}(100)$ with $1 \mathrm{Hm}$ preadsorbed]. The change of activation energy of hydrogen diffusion on oxygen sites changes slightly as well (for $1 \mathrm{Ho}$ system, $\mathrm{E}_{\text {act,BEEF-vdW }}$ $=0.81 \mathrm{eV}$ vs. $\mathrm{E}_{\mathrm{act}, \mathrm{RPBE}}=0.67 \mathrm{eV}$ and for $1 \mathrm{Ho}-1 \mathrm{Hm}$ system, $\mathrm{E}_{\mathrm{act}, \mathrm{BEEF}-\mathrm{vdW}}=1.19 \mathrm{eV}$ vs. $\mathrm{E}_{\text {act, RPBE }}=1.08 \mathrm{eV}$ ). In addition, we have performed $\mathrm{RPBE}+\mathrm{U}$ calculations that are normally used for strongly correlated systems. We have applied $\mathrm{U}=7$ corrections to oxygen $\mathrm{p}$ orbitals. ${ }^{43}$ The bandgap is widened of approximately $0.7 \mathrm{eV}$ compared to the RPBE calculations.
The differential adsorption energy decreases slightly for $1 \mathrm{Ho}$ system [ $\delta \mathrm{E}_{\mathrm{Ho}, \mathrm{RPBE}-\mathrm{U}}=1.27 \mathrm{eV}$ on clean $\mathrm{MgO}(100)$ surface] and little bit more when calculated on $\mathrm{MgO}(100)$ with $1 \mathrm{Hm}$ preadsorbed $\left(\delta \mathrm{E}_{\mathrm{Ho}, \mathrm{RPBE}-\mathrm{U}}=-0.87 \mathrm{eV}\right)$. The activation energies for hydrogen diffusion do not vary significantly compared to RPBE $\left(\mathrm{E}_{\text {act, }, R P B E-\mathrm{U}}=0.89 \mathrm{eV}\right.$ for $1 \mathrm{Ho}$ system and $\mathrm{E}_{\text {act,RPBE-U }}$ $=1.05 \mathrm{eV}$ for $1 \mathrm{Ho}-1 \mathrm{Hm}$ system). Therefore even though the values are slightly different, the trends in binding and activation energies are the same using BEEF-vdW, RPBE, and $\mathrm{RPBE}+\mathrm{U}$. The hydrogen diffusion paths keep being the same for all three tested functionals, with only small differences in the distance between the adsorbates and the surface. The zero point energy corrections keep in the same trends (for $1 \mathrm{Ho}$ initial systems, $\mathrm{E}_{\mathrm{ZPE}, \mathrm{RPBE}}=0.29 \mathrm{eV}, \mathrm{E}_{\mathrm{ZPE}, \mathrm{RPBE}+\mathrm{U}}=0.29 \mathrm{eV}$, $\mathrm{E}_{\mathrm{ZPE}, \mathrm{BEEF}-\mathrm{vdW}}=0.25 \mathrm{eV}$, while for structures in transition state, $\mathrm{E}_{\mathrm{ZPE}, \mathrm{RPBE}}=0.04 \mathrm{eV}, \mathrm{E}_{\mathrm{ZPE}, \mathrm{RPBE}-\mathrm{U}}=0.08 \mathrm{eV}, \mathrm{E}_{\mathrm{ZPE}, \mathrm{BEEF}-\mathrm{vdW}}$ $=0.06 \mathrm{eV}$ ). We thus are confident enough that RPBE calculations would correctly reproduce the surface properties and we do not need to run more computationally demanding methods.

To facilitate convergences, the Kohn-Sham states were populated using a Fermi-Dirac distribution with an electronic temperature of $\mathrm{k}_{\mathrm{b}} \mathrm{T}=0.1 \mathrm{eV}$ and the total energies are extrapolated to $\mathrm{k}_{\mathrm{b}} \mathrm{T}=0 \mathrm{eV}$. The lattice constant of bulk $\mathrm{MgO}$ is calculated equal to $4.31 \AA$. The bare $\mathrm{MgO}(100)$ surface is modeled with 12 atomic layers of which 8 are kept frozen and the adsorption is investigated in a $(3 \times 3)$ surface cell. Because the unit cell is large, the surface Brillouin zone is sampled with a $1 \times 1 \times 1$ Monkhorst-Pack k-point grid (Gamma point). The subsequent slabs are separated by a $20 \AA$ of vacuum space in the $\mathrm{z}$ direction, and a dipole correction has been applied to compensate for the effect of adsorbing molecules only on one side of the surface. The geometries were optimized using a force convergence criterion of $0.05 \mathrm{eV} / \AA$.

The energy associated with the two distinct binding sites of the $\mathrm{MgO}(100)$ surface is dependent on the lack/presence of a co-adsorbate. By adding one hydrogen atom at a time to the surface, the differential adsorption energy per $\mathrm{H}$ atom is calculated as

$$
\delta \mathrm{E}_{\mathrm{H}^{*}}=\mathrm{E}_{\mathrm{nH}}-\mathrm{E}_{(\mathrm{n}-1) \mathrm{H}^{*}}-\mathrm{E}_{1 / 2 \mathrm{H} 2(\mathrm{~g})},
$$

where $E_{n H} *$ and $E_{(n-1) H^{*}}$ are the total energies of the $\mathrm{MgO}$ surface with $\mathrm{n}$ and $(\mathrm{n}-1) \mathrm{H}$ atoms adsorbed ( $\mathrm{n}$ can indicate atoms adsorbed on the $\mathrm{O}$-site, $\mathrm{Mg}$-site, or both). $\mathrm{E}_{1 / 2 \mathrm{H} 2(\mathrm{~g})}$ is the energy of a hydrogen atom in the gas phase from the $\mathrm{H}_{2}$ molecule.

The climbing image nudged elastic band (NEB) method ${ }^{44}$ was used to locate the transition state (TS) of hydrogen diffusion. Vibration frequency analysis calculations were carried out to ensure that initial, transition, and final states are true local minimum (transition state) or maximum (initial and final states) and also to enable the calculations of zero point energies (ZPE). Electron charges are analyzed according to the Bader method. ${ }^{45}$ The activation energy $\left(\Delta \mathrm{E}_{\mathrm{a}}\right)$ is calculated as the difference between the energy of the transition state and the energy of the initial structure. All the structures used in this work and the scripts to run and analyze the calculations are available on FigShare. ${ }^{48}$ 


\section{RESULTS AND DISCUSSIONS}

\section{A. Hydrogen diffusion to O-sites}

For brevity, the detailed effects of cooperative binding on differential adsorption of $\mathrm{H}$ on $\mathrm{MgO}(100)$ are reported in the supplementary material (Fig. S1), and it can partially be derived from our previous work. ${ }^{26}$ In the following, we investigate the effects of the donor-acceptor interaction between the adsorbed atoms $\left(\mathrm{H}^{+} / \mathrm{H}^{-}\right)$on the reaction path and transition state of hydrogen diffusion on $\mathrm{MgO}(100)$.

The energy profile for $\mathrm{H}$ hopping on $\mathrm{O}$-sites is shown in Fig. 1 for the ground state configurations of co-adsorbed hydrogens $(1 \mathrm{Ho}, 1 \mathrm{Ho}-1 \mathrm{Hm}, 2 \mathrm{Ho}-1 \mathrm{Hm}, 2 \mathrm{Ho}-2 \mathrm{Hm}-$ the top and side views of the initial, transition, and final unit cell configuration are pictured in Fig. S2 of the supplementary material). The diffusion from $\mathrm{O}$ to $\mathrm{Mg}$ sites or from $\mathrm{Mg}$ to $\mathrm{O}$ sites has a lower probability to take place due to the fact that in all cases it would end in less stable structures: for example, for the $1 \mathrm{H}$ configuration, it would end in $1 \mathrm{Hm}$ which is less stable than $1 \mathrm{Ho}$, while $2 \mathrm{H}$ would end in $2 \mathrm{Hm}$ or $2 \mathrm{Ho}$ which are also less stable than $1 \mathrm{Ho}-1 \mathrm{Hm}$ and so on (the relative stabilities are reported in Table S1 of the supplementary material). This explains the focus of our research only on diffusion from $\mathrm{O}$ to $\mathrm{O}$ and from $\mathrm{Mg}$ to $\mathrm{Mg}$ sites since it preserves the ground state configurations of co-adsorbed hydrogens.

For $\mathrm{H}$ hopping on $\mathrm{O}$ sites, the diffusion barriers show two different shapes [Fig. 1(a)]: for the unpaired $\mathrm{H}$ systems, the barriers are considerably broader near the top, while for paired $\mathrm{H}$ systems, they have a parabolic shape. Similar behaviors have already been predicted for different metals. ${ }^{46,47}$ During the diffusion pathway for the unpaired systems, Ho, at a short distance from the initial state (IS) $(\mathrm{d}=0.6-0.7 \AA)$, rises above the surface close to the height of $\mathrm{H}$ in the transition state and afterwards diffuses at the same vertical distance from the surface very close the final state (FS) $(\mathrm{d}=2.4-2.6 \AA$ relative to the initial distance, when the TS is at $1.5 \AA$ ). In the paired configuration, the distance between the diffusing Ho and the surface changes gradually from the initial to the transition state and to the final state, with $\mathrm{H}$ staying in contact with the oxygen during the transition. The imaginary frequency along the reaction coordinate for Ho paired systems is $1177 \mathrm{~cm}^{-1}$ and corresponds to typical proton transfer reaction barriers. For the unpaired $\mathrm{H}$ systems that have the broad top barriers, the TS have a much smaller imaginary frequency $\left(\approx 240 \mathrm{~cm}^{-1}\right)$ and indicate a much weaker bond. We do not get further inside the quantum nature of hydrogen diffusion, to include, for example, tunneling effects, ${ }^{47}$ because is beyond the purpose of our study.

In Fig. 1(b), we calculate the energetics of the transitions for paired and unpaired configurations. In particular, we investigate the activation energy $\left(\Delta \mathrm{E}_{\mathrm{a}}\right)$, calculated relative to initial and final structures, and the differential adsorption energy of $\mathrm{H}$ atoms $\left(\delta \mathrm{E}_{\mathrm{ads}, \mathrm{H}}\right)$. As pointed out in our previous work, ${ }^{26}$ the pairing energy (or cooperative binding) is large $\left(\Delta \mathrm{E}_{\text {pairing }}\right.$ around $\left.2 \mathrm{eV}\right)$. This makes the adsorption of an additional Ho that adsorbs on a configuration with an unpaired $1 \mathrm{Hm}$ (i.e. on $1 \mathrm{Hm}, 1 \mathrm{Ho}-2 \mathrm{Hm}$ ) much more favorable than on a configuration with an already paired $\mathrm{H}$ (i.e., on $1 \mathrm{Ho}-1 \mathrm{Hm}) .{ }^{26}$

For the 1 Ho structure, the minimum energy path indicates that the structure of the transition state has the hydrogen atom in the bridge position (two $\mathrm{Mg}$ or two $\mathrm{O}$ atoms) at a distance of $\mathrm{d}=2.56$ A relative to the two neighboring Mg atoms [Fig. 1(c)]. The activation energy required to traverse this path is around $0.7 \mathrm{eV}$ (Table I). When taking zero point energy (ZPE) effects into account, the adsorption energy of $\mathrm{H}$ atom on oxygen shifts up by around $0.3 \mathrm{eV}$, while in the transition state, it shifts up only approximately $0.04 \mathrm{eV}$. Therefore the activation energy will decrease to about $0.4 \mathrm{eV}$ (Table I, in parenthesis). The difference in ZPE corrections for $\mathrm{H}$ in the IS/FS and in the TS is due to the two vibrational frequencies that at the TS state are substantially lower than the three degenerate vibrational frequencies for $\mathrm{H}$ in the IS/FS. They are different due to the
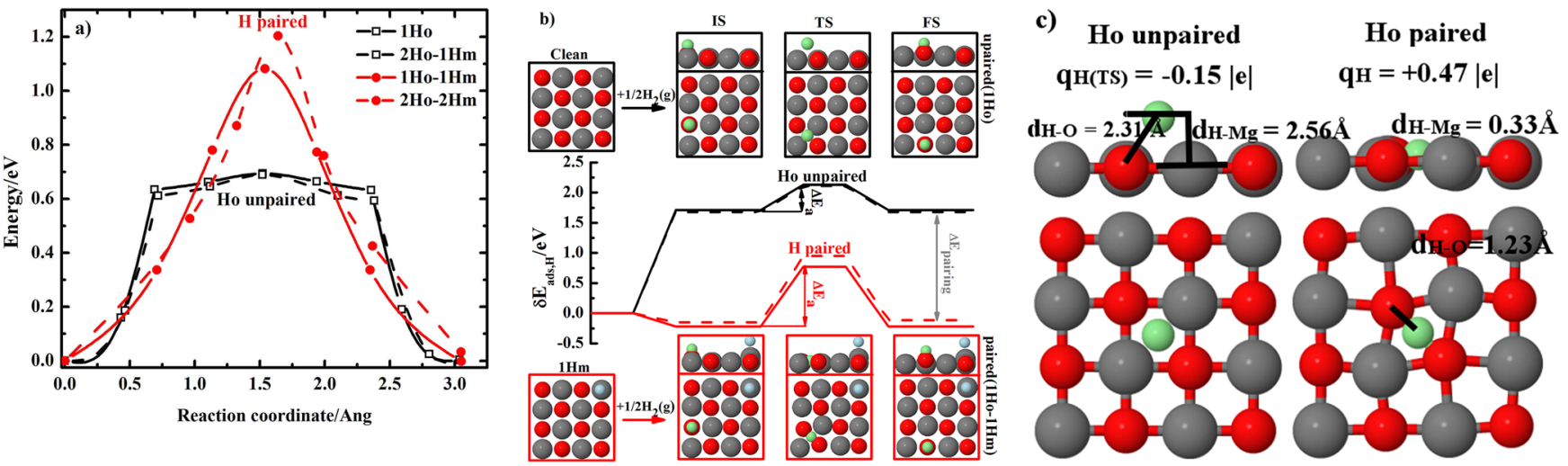

FIG. 1. (a) Energy barriers of the $\mathrm{H}$ diffusion paths between O-sites for unpaired ( $\mathrm{H}$ on oxygen is always unpaired in odd systems-see the Ho unpaired label) and paired $\mathrm{H}$ ground state configurations: solid $(1 \mathrm{Ho}) /$ dashed $(2 \mathrm{Ho}-1 \mathrm{Hm})$ black lines and solid $(1 \mathrm{Ho}-1 \mathrm{Hm}) / \mathrm{dashed}(2 \mathrm{Ho}-2 \mathrm{Hm})$ red lines, respectively. (b) The minimum energy path for the most stable configurations for $1 \mathrm{H}(1 \mathrm{Ho}), 2 \mathrm{H}(1 \mathrm{Ho}-1 \mathrm{Hm}), 3 \mathrm{H}(2 \mathrm{Ho}-1 \mathrm{Hm})$, and $4 \mathrm{H}(2 \mathrm{Ho}-2 \mathrm{Hm})$ with $\mathrm{ZPE}$ corrections. The first horizontal lines indicate the adsorption energy of 1 Ho on clean (black solid), on 1Ho-1Hm (dashed black), on $1 \mathrm{Hm}$ (red solid), and on $1 \mathrm{Ho}-2 \mathrm{Hm}$ (red dashed). Top and side views of $1 \mathrm{Ho}$ and of $1 \mathrm{Ho}-1 \mathrm{Hm}$ - initial (IS), transition (TS), and final (FS) states are shown. The structures of $2 \mathrm{Ho}-1 \mathrm{Hm}$ and $2 \mathrm{Ho}-2 \mathrm{Hm}$ are similar to the structures of $1 \mathrm{Ho}$ and $1 \mathrm{Ho}-1 \mathrm{Hm}$ (as shown in Fig. S2 of the supplementary material). (c) Structure of the transition states of $1 \mathrm{Ho}$ and $1 \mathrm{Ho}-1 \mathrm{Hm}$. The charge on $\mathrm{H}$ and $\mathrm{HeO} / \mathrm{HeMg}$ distances are reported. Hydrogen atoms are coloured as follows: light blue spheres for the $\mathrm{H}$ atoms preadsorbed (which do not diffuse) and light green for $\mathrm{H}$ atoms that diffuse. Oxygen atoms are represented by red, while magnesium by gray spheres. 
TABLE I. Activation energy of hydrogen diffusion from $\mathrm{O}^{2-}$ to another $\mathrm{O}^{2-}$ (the values in parentheses are with $\mathrm{ZPE}$ corrections), Bader charges for initial and transition states, $\mathrm{O}-\mathrm{O}$ and $\mathrm{Mg}-\mathrm{Mg}$ lattice distances.

\begin{tabular}{|c|c|c|c|c|c|c|}
\hline Adsorbates & $\begin{array}{l}E_{a} \\
(e V)\end{array}$ & $\begin{array}{c}\text { qIS (fragment) } \\
\text { lel }\end{array}$ & $\begin{array}{c}\mathrm{q}_{\mathrm{TS}} \text { (fragment) } \\
\text { lel }\end{array}$ & $\begin{array}{c}\mathrm{d}_{\mathrm{H}-\mathrm{Mg}} \\
(\AA)^{\mathrm{a}}\end{array}$ & $\begin{array}{c}\mathrm{d}_{\mathrm{O}-\mathrm{O}} \\
(\AA)\end{array}$ & $\begin{array}{c}\mathrm{d}_{\mathrm{Mg}-\mathrm{Mg}} \\
(\AA)\end{array}$ \\
\hline Clean slab & $\ldots$ & $\ldots$ & $\ldots$ & $\ldots$ & 3.046 & 3.048 \\
\hline $1 \mathrm{Ho}$ & $0.67(0.41)$ & $+0.56(1 \mathrm{Ho})$ & $-0.15(1 \mathrm{Ho})$ & 2.56 & 3.097 & 3.060 \\
\hline $1 \mathrm{Ho} / 1 \mathrm{Hm}$ & $1.08(0.98)$ & $\begin{array}{l}+0.58(1 \mathrm{Ho}) \\
-0.69(1 \mathrm{Hm})\end{array}$ & $\begin{array}{l}+0.47(1 \mathrm{Ho}-\mathrm{TS}) \\
-0.69(1 \mathrm{Hm})\end{array}$ & 0.33 & 2.51 & 3.63 \\
\hline $1 \mathrm{Ho} / 1 \mathrm{CH}_{3} \mathrm{Om}$ & $1.08(0.98)$ & $\begin{array}{l}+0.56(1 \mathrm{Ho}) \\
-0.76\left(1 \mathrm{CH}_{3} \mathrm{Om}\right)\end{array}$ & $\begin{array}{l}+0.48(1 \mathrm{Ho}-\mathrm{TS}) \\
-0.75\left(1 \mathrm{CH}_{3} \mathrm{Om}\right)\end{array}$ & 0.32 & 2.53 & 3.45 \\
\hline 1Ho/1HOm & $1.09(0.97)$ & $\begin{array}{l}+0.56(1 \mathrm{Ho}) \\
-0.77(1 \mathrm{HOm})\end{array}$ & $\begin{array}{l}+0.48(1 \mathrm{Ho}-\mathrm{TS}) \\
-0.75(1 \mathrm{HOm})\end{array}$ & 0.34 & 2.51 & 3.63 \\
\hline $2 \mathrm{Ho} / 1 \mathrm{Hm}$ & $0.69(0.43)$ & $\begin{array}{l}+0.49\left(1 \mathrm{Ho}_{1}\right) \\
+0.50\left(1 \mathrm{Ho}_{2}\right) \\
-0.69(1 \mathrm{Hm})\end{array}$ & $\begin{array}{l}-0.34(1 \mathrm{Ho}-\mathrm{TS}) \\
+0.58(1 \mathrm{Ho}) \\
-0.53(1 \mathrm{Hm})\end{array}$ & 1.79 & 3.12 & 2.98 \\
\hline $2 \mathrm{Ho} / 2 \mathrm{Hm}$ & $1.20(1.10)$ & $\begin{array}{l}+0.58\left(1 \mathrm{Ho}_{1}\right) \\
+0.58\left(1 \mathrm{Ho}_{2}\right) \\
-0.69\left(1 \mathrm{Hm}_{1}\right) \\
-0.68\left(1 \mathrm{Hm}_{2}\right)\end{array}$ & $\begin{array}{l}+0.49\left(1 \mathrm{Ho}_{1}-\mathrm{TS}\right) \\
+0.55\left(1 \mathrm{Ho}_{2}\right) \\
-0.68\left(1 \mathrm{Hm}_{1}\right) \\
-0.68\left(1 \mathrm{Hm}_{2}\right)\end{array}$ & 0.44 & 2.51 & 3.62 \\
\hline
\end{tabular}

${ }^{\mathrm{a}}$ The distance is measured relative to the two neighbor Mg atoms [Fig. 1(c)].

way $\mathrm{H}$ binds in the initial and transition states and are reflected by the projected density of state analysis performed below. A comparison of the data with and without ZPE effects is reported in the supplementary material (Fig. S3).

When $2 \mathrm{H}$ are co-adsorbed (1Ho-1Hm), the two atoms are stabilized by their cooperative interaction and the diffusion takes place through the surface (bridge position) with a distortion of the neighboring atoms in the xy-plane, i.e., the two oxygen atoms get closer to the hydrogen in the transition state and with magnesium atoms getting further from it [Fig. 1(c), the distances are also reported in Table I]. A higher activation energy of around $1.1 \mathrm{eV}$ is required. With ZPE corrections, this energy decreases to around $1 \mathrm{eV}$. In this case, the two vibrational frequencies of the TS state, that are used to calculate the ZPE correction, are still lower than the ones for $\mathrm{H}$ in the IS/FS but not as small compared to the ones of the TS of unpaired $\mathrm{H}$.

The system with $3 \mathrm{H}$ adsorbed, i.e., $2 \mathrm{Ho}-1 \mathrm{Hm}$, behaves in a similar way as $1 \mathrm{Ho}$, and similar values for the adsorption energy and diffusion path of the system $1 \mathrm{Ho}-1 \mathrm{Hm}$ have been calculated for the system $2 \mathrm{Ho}-2 \mathrm{Hm}$.

The charge on $\mathrm{H}$ in the $1 \mathrm{Ho}$ system changes from positive in the initial state $(q=+0.56$ lel $)$ to slightly negative in the transition state $(q=-0.15$ lel $)$, while for the $1 \mathrm{Ho}-1 \mathrm{Hm}$ configuration the charge variation on hydrogen from the initial to transition state is much smaller and always positive (from +0.58 to +0.47 lel). Similar charges have also been found for the other two configurations, $2 \mathrm{Ho}-1 \mathrm{Hm}$ and $2 \mathrm{Ho}-2 \mathrm{Hm}$ (Table I and $\mathrm{S} 1$ of the supplementary material).

If hydroxyl or methoxyl is co-adsorbed instead on hydrogen on the $\mathrm{Mg}$-site $\left(1 \mathrm{HO}, 1 \mathrm{CH}_{3} \mathrm{O}\right)$, the diffusion path and activation energies for Ho remain the same as for $1 \mathrm{Ho}-1 \mathrm{Hm}$ (through the surface top layer showing a distortion of the atoms in the xy-plane). This shows that the interaction between donor and acceptor fragments is independent both on the distance between the fragments and of their nature. What really matters is their character, i.e., if they are electron donors or acceptors.

The projected densities of states (PDOS) of relevant configurations are shown in Figs. 2(a)-2(f) for the initial/final and transition states. In the initial state, the orbitals of $\mathrm{H}$ adsorbed on oxygen, in 1Ho [Fig. 2(b)], are occupied, with a strong mixing between the $\mathrm{O}-2 \mathrm{p}$ states and $\mathrm{H}-1 \mathrm{~s}$ states, indicating a covalent binding. Since the $\mathrm{H}$ has donated one electron, the Fermi level shifts up to the conduction band edge. When a $1 \mathrm{Hm}$ is co-adsorbed on the $1 \mathrm{Ho}$ configuration [1Ho-1Hm, Fig. 2(d)], an additional state is present in the bandgap below the Fermi level, which indicates no covalent bond with the surface because the mixing between $1 \mathrm{Hm}$ and $\mathrm{Mg}-3 \mathrm{~s}$ or O-2p states is low. The presence of these states in the bandgap has already been shown in previous work at higher level of theory. ${ }^{26}$ In the transition state for the unpaired system 1Ho [Fig. 2(c)], the H states previously occupied splits now in two orbitals, one occupied and one empty, both closer to the Fermi level. A shift of the Fermi level, from the conduction band (CB) to the middle of the gap, is thus observed during the transition state. This shift is confirmed by the analysis of the charge that shows a fraction of electron transferring from the surface to $\mathrm{H}$ in the TS. The changes of hydrogen states from initial to transition states are also an explanation of significant variation of vibrational frequencies when $\mathrm{H}$ is in the initial or transition state.

On the other side, there is no change in the PDOS for 1Ho1Hm [Fig. 2(e)] from the IS to the TS: the covalent bond is preserved during the transition as shown by the Bader charges (Table I). These PDOS are clear evidences that the cooperative 

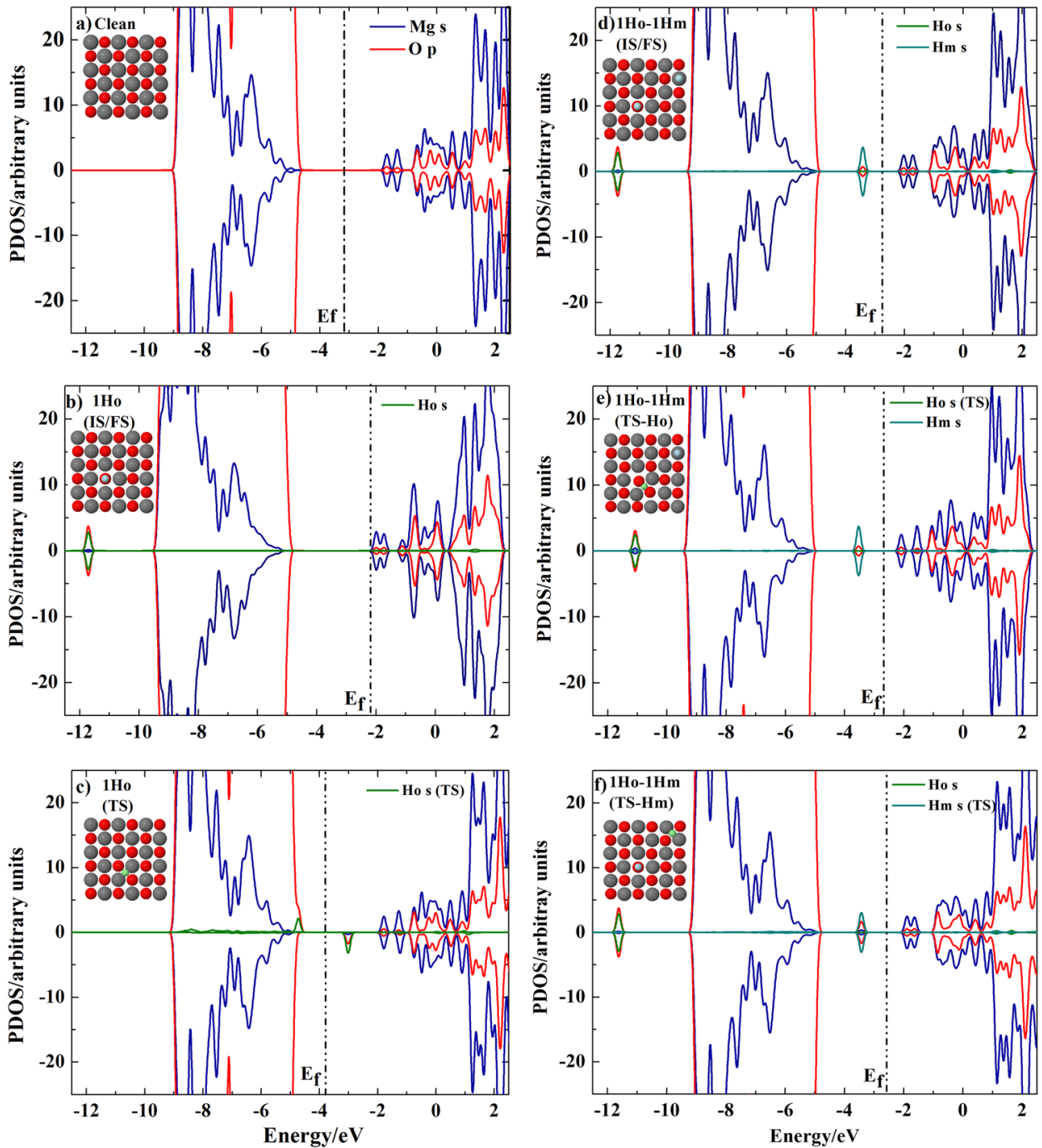

FIG. 2. Projected density of states (PDOS) of MgO for the clean surface (a) and for different combination of adsorbates: initial/final and transition state of $1 \mathrm{Ho}$ [(b) and (c)], initial/final state of $1 \mathrm{Ho}-1 \mathrm{Hm}(\mathrm{d})$, and transition state of 1Ho-1Hm when $\mathrm{H}$ hops between oxygen and magnesium atoms [(e) and (f)]. The positive PDOS indicates the spinup channel and the negative PDOS the spin-down channel. The structure of the surface is also indicated.

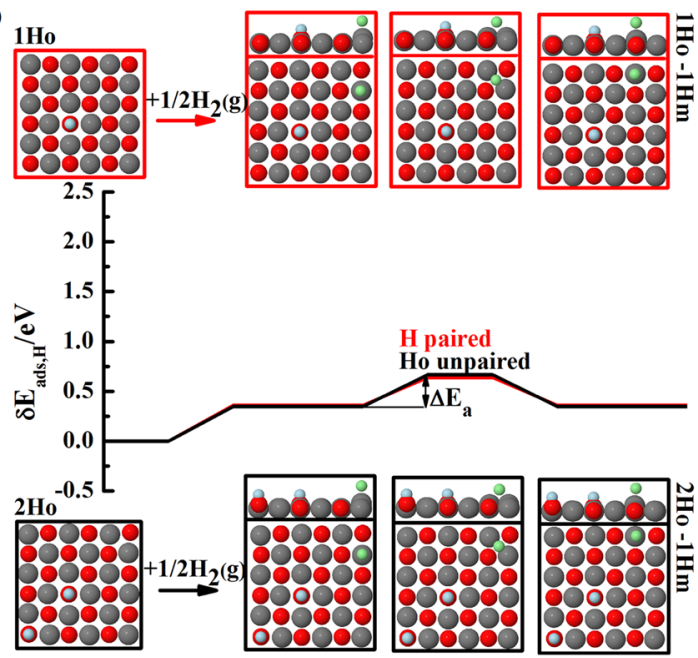

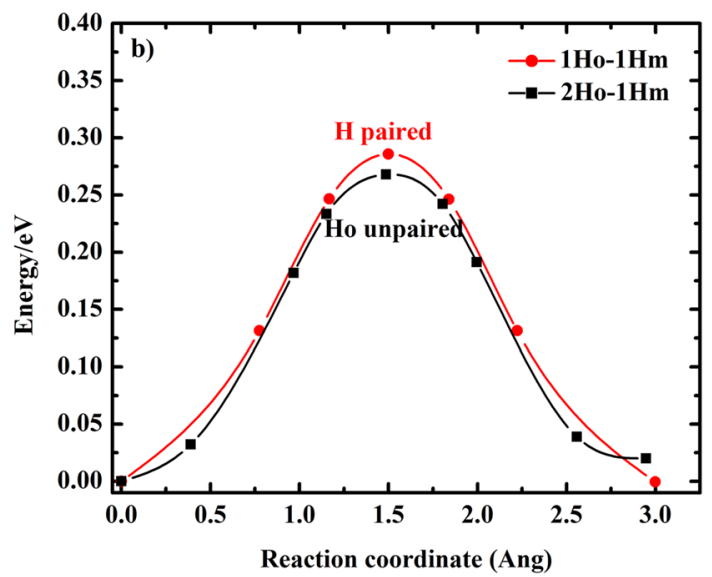

c) $\mathbf{q H}(\mathbf{T S})=-0.71|\mathrm{e}|$

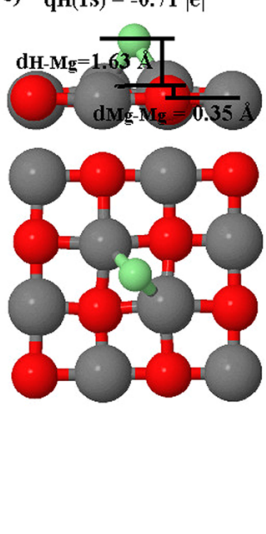

FIG. 3. (a) The minimum energy path of $\mathrm{H}$ hopping from one $\mathrm{Mg}$ to the neighboring one for the most stable structures of $2 \mathrm{H}$, $3 \mathrm{H}$ atoms on $\mathrm{MgO}(100)$ surface: $1 \mathrm{Ho}-1 \mathrm{Hm}$ (red solid line) and $2 \mathrm{Ho}-1 \mathrm{Hm}$ (black line). To calculate the adsorption energy of $\mathrm{H}$ atom on $\mathrm{Mg}$ site, the reference surfaces are $1 \mathrm{Ho}$ and $2 \mathrm{Ho}$. ZPE corrections are included. (b) The shape of the energy barrier. Both sets of data show a parabolic shape near top (c) Magnifcation of transition states with emphasizing the charge on $\mathrm{H}$ and $\mathrm{H}-\mathrm{O} / \mathrm{H}-\mathrm{Mg}$ distances. Ho unpaired label signifies the systems that have Ho unpaired (2Ho-1Hm). Hydrogen atoms are coloured as follows: light blue spheres for the $\mathrm{H}$ atoms preadsorbed (which do not diffuse) and light green for $\mathrm{H}$ atoms that diffuses between $\mathrm{Mg}$ sites. Oxygen atoms are represented by red and magnesium by gray spheres. 
interaction between the two $\mathrm{H}$ atoms ( $\mathrm{Ho}$ and $\mathrm{Hm}$ ) influence the TS of $\mathrm{H}$ diffusion on the surface, compared to the case when the Ho is not paired.

\section{B. Hydrogen diffusion on Mg sites}

The analysis of $\mathrm{H}$ hopping on $\mathrm{Mg}$ sites is performed on the ground state structures: $1 \mathrm{Ho}-1 \mathrm{Hm}$ and $2 \mathrm{Ho}-1 \mathrm{Hm}$. The adsorption energy of $\mathrm{H}$ on the magnesium site calculated on a system with one $\mathrm{H}$ preadsorbed on the $\mathrm{O}$-site $(1 \mathrm{Ho})$ is weaker than a $\mathrm{H}$ adsorbed on the $\mathrm{O}$-site on the $1 \mathrm{Hm}$ system $(0.36$ and $-0.37 \mathrm{eV}$, respectively, when ZPE corrections have not been included). Since the ground stable configuration for a single hydrogen adsorbed is $1 \mathrm{Ho}$ (and not $1 \mathrm{Hm}$ ), it lacks physical meaning to investigate the diffusion in the $1 \mathrm{Hm}$ configurations. For the diffusion on $\mathrm{Mg}$-sites, the number of preadsorbed Ho has no effects on both the differential adsorption and activation energies, as it is shown in Fig. 3(a). This is because the differential adsorption energy for $2 \mathrm{Ho}-1 \mathrm{Hm}$ is calculated relative to the $2 \mathrm{Ho}$ system, and the added $1 \mathrm{Hm}$ forms an electron donor-acceptor pair with one of the two hydrogens adsorbed on the oxygen site, while the second adsorbed hydrogen does not have an effect in further stabilizing the $1 \mathrm{Hm}$ fragment. The shape of the diffusion barrier for these studied systems is conventional, i.e., parabolic [Fig. 3(b)].

For the $1 \mathrm{Ho}-1 \mathrm{Hm}$ system, the activation energy for $\mathrm{H}$ hopping between $\mathrm{Mg}$-sites is three time smaller than the diffusion on O-sites $\left(\mathrm{E}_{\mathrm{a}}=0.3 \mathrm{eV}\right)$. When including ZPE effects, the binding energy of $\mathrm{H}$ for all the states increases by around $0.15 \mathrm{eV}$. Due to this uniform increase of ZPE for both initial/final and transition states, the ZPE effects on the activation energy are not significant.

Similar effects are seen for the $2 \mathrm{Ho}-1 \mathrm{Hm}$ configuration. $\mathrm{H}$ diffuses above the surface at a distance of approximately $1.6 \AA$ (relative to the two neighbor $\mathrm{Mg}$ atoms) with a moderate distortion of the surface atoms around the transition state [with the $\mathrm{Mg}$ atoms moving out of the surface $\approx 0.35 \AA$, Fig. 3(c)]. The charge analysis shows only a small variation of the charge from the initial to transition state of all $\mathrm{H}$ atoms [see Table $\mathrm{S} 2$ (supplementary material) and Table II]. Also in this case, the PDOS of the transition state registers no shifts of the bands compared to the initial state [Fig. 2(f)]. On the other side, a stronger hybridization of $\mathrm{H}-1 \mathrm{~s}$ in the transition state with the $\mathrm{O}-2 \mathrm{p}$ states is observed.

Therefore the highest rate of $\mathrm{H}$ hopping will take place between $\mathrm{Mg}$-sites no matter the number of $\mathrm{H}$ pre-adsorbed (activation barrier $0.3 \mathrm{eV}$ ). At a lower rate, $\mathrm{H}$ diffuses between

TABLE II. Activation energy of hydrogen diffusion on $\mathrm{Mg}$ sites, bader charge for $\mathrm{TS}$, and $\mathrm{O}-\mathrm{O}$ and $\mathrm{Mg}-\mathrm{Mg}$ lattice distances (values in parentheses are with ZPE effects). Bader charges for initial states are in Table I.

\begin{tabular}{lccccc}
\hline \hline Adsorbates & $\begin{array}{c}\mathrm{E}_{\mathrm{a}} \\
(\mathrm{eV})\end{array}$ & $\begin{array}{c}\mathrm{q}_{\mathrm{TS}} \text { (fragment) } \\
\text { lel }\end{array}$ & $\begin{array}{c}\mathrm{d}_{\mathrm{H}-\mathrm{Mg}} \\
(\AA)\end{array}$ & $\begin{array}{c}\mathrm{d}_{\mathrm{O}-\mathrm{O}} \\
(\AA)\end{array}$ & $\begin{array}{c}\mathrm{d}_{\mathrm{Mg}-\mathrm{Mg}} \\
(\AA)\end{array}$ \\
\hline $1 \mathrm{Ho} / 1 \mathrm{Hm}$ & $0.28(0.29)$ & $\begin{array}{l}-0.71(1 \mathrm{Hm}-\mathrm{TS}) \\
+0.56(1 \mathrm{Ho})\end{array}$ & 1.61 & 3.24 & 2.79 \\
\hline $2 \mathrm{Ho} / 1 \mathrm{Hm}$ & $0.31(0.32)$ & $\begin{array}{l}-0.71(1 \mathrm{Hm}-\mathrm{TS}) \\
+0.57(1 \mathrm{Ho})\end{array}$ & 1.58 & 3.28 & 2.79 \\
\hline
\end{tabular}

O-sites when $\mathrm{H}$ is unpaired and, at last, when $\mathrm{H}$ is paired (activation barriers 0.4 and $1 \mathrm{eV}$, respectively).

\section{CONCLUSIONS}

The diffusion of $\mathrm{H}$ atom on $\mathrm{MgO}(100)$ surface has been investigated to understand the effect of the cooperative interaction on the activation energies and reaction paths when multiple $\mathrm{H}$ atoms are adsorbed on the surface in their ground state configuration. Beside the fact that on $\mathrm{MgO}$ surface the co-adsorption of donor-acceptor pairs leads to a strengthening of the adsorption energy compared to the case when are adsorbed alone in the cell (cooperative interaction), we have shown that co-adsorption influences the hydrogen diffusion. The results obtained here, can be generalized for a higher number of $\mathrm{H}$, showing the same trends in variation of the activation energy for $\mathrm{H}$ diffusion on $\mathrm{O}$ sites, when passing from unpaired to paired adsorbed hydrogens in their ground state configurations. In particular, the activation energy is higher for a system with paired adsorbed hydrogens. The diffusion paths changes as well: for paired $\mathrm{H}$, Ho moves above the surface with a charge transfer from the surface to $\mathrm{H}$ atom, while for unpaired $\mathrm{H}$, Ho moves through the surface with no charge transfer during the TS. Two distinct shapes of diffusion barriers have been identified: a conventional parabolic slope corresponding to the $\mathrm{H}$ diffusion between oxygen sites in paired configurations and a broader shape for unpaired situations.

For the $\mathrm{H}$ hopping on $\mathrm{Mg}$-sites, the activation energy, which is lower than the corresponding energy for $\mathrm{H}$ hopping on the O-site, does not depend on the number of preadsorbed fragments. We expected that the diffusion on $\mathrm{Mg}$ sites takes place at a higher rate than on $\mathrm{O}$ sites but not significantly higher compared to the case of unpaired $\mathrm{H}$.

\section{SUPPLEMENTARY MATERIAL}

See supplementary material for 3 figures and 2 tables. The figures report the differential adsorption energies of $\mathrm{H}$ on $\mathrm{O}$ and $\mathrm{Mg}$ sites for $1 \mathrm{H}, 2 \mathrm{H}, 3 \mathrm{H}, 4 \mathrm{H}$ structures; top and lateral views of the used unit cells of the most stable structures for $1 \mathrm{H}(1 \mathrm{Ho}), 2 \mathrm{H}(1 \mathrm{Ho}-1 \mathrm{Hm}), 3 \mathrm{H}(2 \mathrm{Ho}-1 \mathrm{Hm})$ and $4 \mathrm{H}(2 \mathrm{Ho}-2 \mathrm{Hm})$ for their initial, transition, and final states, potential energy surface for $\mathrm{H}$ diffusion from $\mathrm{O}$ to $\mathrm{O}$ without and with $\mathrm{ZPE}$ corrections; the differential adsorption energy of $\mathrm{H}$ on oxygen site when on $\mathrm{Mg}$ site are co-adsorbed $\mathrm{H}, \mathrm{HO}, \mathrm{CH}_{3} \mathrm{O}$ fragments. The tables report all possible structures for $1 \mathrm{H}, 2 \mathrm{H}, 3 \mathrm{H}$ systems and their relative stabilities; $\mathrm{H}$ distances from the surface and charges.

\section{ACKNOWLEDGMENTS}

I.C.M. appreciates financial support from Bridge Grant Contract No. 27BG/2016, AromaVer, Executive Agency for Higher Education, Research, Development and Innovation (UEFISCDI).

\footnotetext{
${ }^{1}$ S. Prada, L. Giordano, and G. Pacchioni, "Charging of gold atoms on doped $\mathrm{MgO}$ and $\mathrm{CaO}$ : Identifying the key parameters by DFT calculations," J. Phys. Chem. C 117, 9943-9951 (2013).

${ }^{2}$ S. Tosoni, D. Spinnato, and G. Pacchioni, "DFT study of $\mathrm{CO}_{2}$ activation on doped and ultrathin MgO films," J. Phys. Chem. C 119, 27594-27602 (2015).
} 
${ }^{3}$ C. Di Valentin, A. Del Vitto, G. Pacchioni, S. Abbet, A. S. Wörz, K. Judai, and U. Heiz, "Chemisorption and reactivity of methanol on $\mathrm{MgO}$ thin films," J. Phys. Chem. B 106, 11961-11969 (2002).

${ }^{4} \mathrm{~K}$. Honkala, A. Hellman, and H. Grönbeck, "Water dissociation on $\mathrm{MgO} / \mathrm{Ag}(100)$ : Support induced stabilization or electron pairing?," J. Phys. Chem. C 114, 7070-7075 (2010).

${ }^{5}$ H. A. Hussein, J. B. A. Davis, and R. L. Johnston, "DFT global optimisation of gas-phase and $\mathrm{MgO}$-supported sub-nanometre AuPd clusters," Phys. Chem. Chem. Phys. 18, 26133-26143 (2016).

${ }^{6}$ A. Markmann, J. L. Gavartin, and A. L. Shluger, "Chemisorption of $\mathrm{HCl}$ to the $\mathrm{MgO}(001)$ surface: A DFT study," Phys. Chem. Chem. Phys. 8, 4359-4367 (2006).

${ }^{7}$ V. K. Díez, J. I. Di Cosimo, C. Ferreti, and C. R. Apesteguía, "Chapter 1: Basic catalysis on $\mathrm{MgO}$ : Generation, characterization and catalytic properties of active sites," in Catalysis (SPR-Catalysis, 2014).

${ }^{8}$ K. Christmann, "Interaction of hydrogen with solid surfaces," Surf. Sci. Rep. 9, 1-163 (1988).

${ }^{9}$ A. Züttel, "Materials for hydrogen storage," Mater. Today 6, 24-33 (2003).

${ }^{10} \mathrm{C}$. Weidenthaler and M. Felderhoff, "Solid-state hydrogen storage for mobile applications: Quo Vadis?," Energy Environ. Sci. 4, 2495-2502 (2011).

${ }^{11}$ A. A. Latimer, A. R. Kulkarni, H. Aljama, J. H. Montoya, J. S. Yoo, C. Tsai, F. Abild-Pedersen, F. Studt, and J. K. Norskov, "Understanding trends in C-H bond activation in heterogeneous catalysis," Nat. Mater. 16, 225-229 (2017).

${ }^{12}$ R. Prins, V. K. Palfi, and M. Reiher, "Hydrogen spillover to nonreducible supports," J. Phys. Chem. C 116, 14274-14283 (2012).

${ }^{13}$ R. Prins, "Hydrogen spillover. Facts and fiction," Chem. Rev. 112, 2714 2738 (2012).

${ }^{14}$ R. Shi, F. Wang, X. Mu, Y. Li, X. Huang, and W. Shen, "MgO-supported $\mathrm{Cu}$ nanoparticles for efficient transfer dehydrogenation of primary aliphatic alcohols," Catal. Commun. 11, 306-309 (2009).

${ }^{15}$ M. B. Ley, L. H. Jepsen, Y.-S. Lee, Y. W. Cho, J. M. Bellosta von Colbe, M. Dornheim, M. Rokni, J. O. Jensen, M. Sloth, Y. Filinchuk, J. E. Jørgensen, F. Besenbacher, and T. R. Jensen, "Complex hydrides for hydrogen storage-New perspectives," Mater. Today 17, 122-128 (2014).

${ }^{16} \mathrm{G}$. Barkhordarian, T. Klassen, and R. Bormann, "Effect of $\mathrm{Nb}_{2} \mathrm{O}_{5}$ content on hydrogen reaction kinetics of Mg," J. Alloys Compd. 364, 242-246 (2004).

${ }^{17} \mathrm{~S}$. Er, G. A. de Wijs, and G. Brocks, "Tuning the hydrogen storage in magnesium alloys," J. Phys. Chem. Lett. 1, 1982-1986 (2010).

${ }^{18} \mathrm{G}$. Wu, J. Zhang, Y. Wu, Q. Li, K. Chou, and X. Bao, "Adsorption and dissociation of hydrogen on MgO surface: A first-principles study," J. Alloys Compd. 480, 788-793 (2009).

${ }^{19}$ I. A. Pašti, M. Baljozović, and N. V. Skorodumova, "Adsorption of nonmetallic elements on defect-free $\mathrm{MgO}(001)$ surface-DFT study," Surf. Sci. 632, 39-49 (2015).

${ }^{20}$ H. Kobayashi, D. R. Salahub, and T. Ito, "Dissociative adsorption of hydrogen molecule on $\mathrm{MgO}$ surfaces studied by the density functional method," J. Phys. Chem. 98, 5487-5492 (1994).

${ }^{21}$ H.-Y. T. Chen, L. Giordano, and G. Pacchioni, "From heterolytic to homolytic $\mathrm{H}_{2}$ dissociation on nanostructured $\mathrm{MgO}(001)$ films as a function of the metal support," J. Phys. Chem. C 117, 10623-10629 (2013).

${ }^{22}$ S. Coluccia, F. Boccuzzi, G. Ghiotti, and C. Mirra, "Evidence for heterolytic dissociation of $\mathrm{H}_{2}$ on the surface of thermally activated $\mathrm{MgO}$ powders," $\mathrm{Z}$. Phys. Chem. 121, 141 (1980).

${ }^{23} \mathrm{~B}$. Li and $\mathrm{H}$. Metiu, "Does halogen adsorption activate the oxygen atom on an oxide surface? I. A study of $\mathrm{Br}_{2}$ and $\mathrm{HBr}$ adsorption on $\mathrm{La}_{2} \mathrm{O}_{3}$ and $\mathrm{La}_{2} \mathrm{O}_{3}$ doped with $\mathrm{Mg}$ or Zr," J. Phys. Chem. C 116, 4137-4148 (2012).

${ }^{24} \mathrm{~N}$. Zobel and F. Behrendt, "Activation energy for hydrogen abstraction from methane over Li-doped MgO: A density functional theory study," J. Chem. Phys. 125, 074715 (2006)

${ }^{25}$ M. Chiesa, M. C. Paganini, E. Giamello, D. M. Murphy, C. Di Valentin, and G. Pacchioni, "Excess electrons stabilized on ionic oxide surfaces," Acc. Chem. Res. 39, 861-867 (2006).

${ }^{26}$ I. E. Castelli, I.-C. Man, S.-G. Soriga, V. Parvulescu, N. B. Halck, and J. Rossmeisl, "Role of the band gap for the interaction energy of coadsorbed fragments," J. Phys. Chem. C 121, 18608 (2017).

${ }^{27}$ M. Calatayud, A. Markovits, and C. Minot, "Electron-count control on adsorption upon reducible and irreducible clean metal-oxide surfaces," Catal. Today 89, 269-278 (2004).

${ }^{28}$ M. Calatayud, A. Markovits, M. Menetrey, B. Mguig, and C. Minot, "Adsorption on perfect and reduced surfaces of metal oxides," Catal. Today 85, 125-143 (2003).
${ }^{29}$ T. Ito, M. Kuramoto, M. Yoshioka, and T. Tokuda, "Active sites for hydrogen adsorption on magnesium oxide," J. Phys. Chem. 87, 4411-4416 (1983).

${ }^{30}$ A. L. Shluger, J. D. Gale, and C. R. A. Catlow, "Molecular properties of the magnesia surface," J. Phys. Chem. 96, 10389-10397 (1992).

${ }^{31}$ E. N. Gribov, S. Bertarione, D. Scarano, C. Lamberti, G. Spoto, and A. Zecchina, "Vibrational and thermodynamic properties of $\mathrm{H}_{2}$ adsorbed on $\mathrm{MgO}$ in the 300-20 K interval," J. Phys. Chem. B 108, 16174-16186 (2004).

${ }^{32}$ H. Metiu, S. Chrétien, Z. Hu, B. Li, and X. Sun, "Chemistry of Lewis acid-base pairs on oxide surfaces," J. Phys. Chem. C 116, 10439-10450 (2012).

${ }^{33}$ W. F. Schneider, K. C. Hass, M. Miletic, and J. L. Gland, "Dramatic cooperative effects in adsorption of $\mathrm{NO}_{x}$ on $\mathrm{MgO}(001)$," J. Phys. Chem. B 106, 7405-7413 (2002).

${ }^{34} \mathrm{P}$. Broqvist, H. Grönbeck, E. Fridell, and I. Panas, "Characterization of $\mathrm{NO}_{x}$ species adsorbed on BaO: Experiment and theory," J. Phys. Chem. B 108, 3523-3530 (2004)

${ }^{35}$ G. Pacchioni, "First principles calculations on oxide-based heterogeneous catalysts and photocatalysts: Problems and advances," Catal. Lett. 145, 80 94 (2015).

${ }^{36}$ D. Mei, Q. Ge, J. Szanyi, and C. H. F. Peden, "First-principles analysis of NOx adsorption on anhydrous $\gamma-\mathrm{Al}_{2} \mathrm{O}_{3}$ surfaces," J. Phys. Chem. C 113, 7779-7789 (2009).

${ }^{37}$ J. Enkovaara, C. Rostgaard, J. J. Mortensen, J. Chen, M. Dułak, L. Ferrighi, J. Gavnholt, C. Glinsvad, V. Haikola, H. A. Hansen, H. H. Kristoffersen, M. Kuisma, A. H. Larsen, L. Lehtovaara, M. Ljungberg, O. Lopez-Acevedo, P. G. Moses, J. Ojanen, T. Olsen, V. Petzold, N. A. Romero, J. StausholmMøller, M. Strange, G. A. Tritsaris, M. Vanin, M. Walter, B. Hammer, H. Häkkinen, G. K. H. Madsen, R. M. Nieminen, J. K. Nørskov, M. Puska, T. T. Rantala, J. Schiøtz, K. S. Thygesen, and K. W. Jacobsen, "Electronic structure calculations with GPAW: A real-space implementation of the projector augmented-wave method," J. Phys.: Condens. Matter 22, 253202 (2010).

${ }^{38}$ J. J. Mortensen, L. B. Hansen, and K. W. Jacobsen, "Real-space grid implementation of the projector augmented wave method," Phys. Rev. B 71, 035109 (2005).

${ }^{39}$ A. H. Larsen, J. J. Mortensen, J. Blomqvist, I. E. Castelli, R. Christensen, M. Dułak, J. Friis, M. N. Groves, B. Hammer, C. Hargus, E. D. Hermes, P. C. Jennings, P. B. Jensen, J. Kermode, J. R. Kitchin, E. L. Kolsbjerg, J. Kubal, K. Kaasbjerg, S. Lysgaard, J. B. Maronsson, T. Maxson, T. Olsen, L. Pastewka, A. Peterson, C. Rostgaard, J. Schiøtz, O. Schütt, M. Strange, K. S. Thygesen, T. Vegge, L. Vilhelmsen, M. Walter, Z. Zeng, and K. W. Jacobsen, "The atomic simulation environment-A Python library for working with atoms," J. Phys.: Condens. Matter 29, 273002 (2017).

${ }^{40}$ B. Hammer, L. B. Hansen, and J. K. Nørskov, "Improved adsorption energetics within density-functional theory using revised Perdew-Burke-Ernzerhof functionals," Phys. Rev. B 59, 7413 (1999).

${ }^{41}$ M. Bajdich, J. K. Nørskov, and A. Vojvodic, "Surface energetics of alkalineearth metal oxides: Trends in stability and adsorption of small molecules," Phys. Rev. B 91, 155401 (2015).

${ }^{42}$ J. Wellendorff, K. T. Lundgaard, A. Møgelhøj, V. Petzold, D. D. Landis, J. K. Nørskov, T. Bligaard, and K. W. Jacobsen, "Density functionals for surface science: Exchange-correlation model development with Bayesian error estimation," Phys. Rev. B 85, 235149 (2012).

${ }^{43}$ D. O. Scanlon, A. Walsh, B. J. Morgan, M. Nolan, J. Fearon, and G. W. Watson, "Surface sensitivity in lithium-doping of $\mathrm{MgO}$ : A density functional theory study with correction for on-site Coulomb interactions," J. Phys. Chem. C 111, 7971-7979 (2007).

${ }^{44}$ G. Henkelman, B. P. Uberuaga, and H. Jónsson, "A climbing image nudged elastic band method for finding saddle points and minimum energy paths," J. Chem. Phys. 113, 9901-9904 (2000).

${ }^{45}$ G. Henkelman, A. Arnaldsson, and H. Jónsson, "A fast and robust algorithm for Bader decomposition of charge density," Comput. Mater. Sci. 36, 354360 (2006).

${ }^{46}$ L. Kristinsdóttir and E. Skúlason, "A systematic DFT study of hydrogen diffusion on transition metal surfaces," Surf. Sci. 606, 1400-1404 (2012).

${ }^{47}$ W. Fang, J. O. Richardson, J. Chen, X.-Z. Li, and A. Michaelides, "Simultaneous deep tunneling and classical hopping for hydrogen diffusion on metals," Phys. Rev. Lett. 119, 126001 (2017).

${ }^{48}$ FigShare-A repository where users can make all their research outputs available in a citable, shareable, and discoverable manner. 